\title{
Lessons from COVID-19 pandemic and the Morocco's success story
}

Benksim Abdelhafid ${ }^{1}$, Ait addi Rachid ${ }^{2}$, El adlani Sana ${ }^{3}$, Cherkaoui Mohamed ${ }^{4}$

${ }^{1} \mathrm{PhD}$, Higher Institute of Nursing Professions and Health Techniques, Health Department of Marrakech-Safi, 40000 Marrakesh, Morocco.

${ }^{2}$ MD, Laboratory of Human Ecology, Faculty of Sciences Semlalia, Cadi Ayyad University, 40000 Marrakesh, Morocco.

${ }^{3}$ MSc, Higher Institute of Nursing Professions and Health Techniques, Health Department of Marrakech-Safi, 40000 Marrakesh, Morocco.

${ }^{4} \mathrm{PhD}$, Laboratory of Human Ecology, Faculty of Sciences Semlalia, Cadi Ayyad University, 40000 Marrakesh, Morocco

Type of article: Editorial

\begin{abstract}
The COVID-19 pandemic is the most prevailing health crisis of our time. Since its appearance in Asia, the virus has spread to all continents, claiming many victims. Moreover, crisis-to-crisis management has met with huge cost in resources throughout the world. Initial measures taken by Morocco have so far enabled the country to control the scale of the coronavirus pandemic. Nevertheless, a deadly resurgence of the pandemic became possible in the event of a hasty end to containment. To mitigate the effects of the health crisis, all countries need to adopt appropriate strategies to break out of containment. Of course, the lifting of restrictions should not be absolute at the same time for everyone.
\end{abstract}

Keywords: COVID-19, Coronavirus, Outbreak, Lifting of containment, Morocco

\section{Introduction}

The COVID-19 pandemic is the most commanding health crisis of our time, with the potential to create devastating social, economic and political crises, which will inevitably leave deep scars on humanity (1). From Dec 31, 2019, to Apr 29, 2020, 3,164,876 coronavirus cases had been reported throughout the world, which included 219,467 deaths and 976,073 recovered. The five countries reporting most cases are the United States $(1,038,490)$, Spain $(236,899)$, Italy $(201,505)$, France $(165,911)$ and the United Kingdom $(161,145)$ (2). This COVID-19 pandemic with its exponential power of dissemination has provoked global action, considering that it has affected more than 210 countries around the world - including Morocco, which recorded 4,289 positive cases and 167 deaths (2).

\section{Strategies against COVID-19 pandemic}

The world faces a great challenge as the new coronavirus continues to spread. Countries have developed strategies in many areas, including working arrangements, health services, the economy, and educational establishments (3-4). Furthermore, no one is able to predict the world's pandemic situation for the coming months. This reticence in human nature when confronted with a completely new situation makes any prediction difficult. If, alongside other health measures, containment and social distancing have become one of the priority intervention tools in many countries, they have led to an unprecedented global economic crisis. Faced with this crisis, unprecedented recovery plans have been implemented by the world powers to save the economy and indeed the more vulnerable populations of the planet (3-4). As part of its policy of social distancing, China has encouraged people to stay at home, canceled

\section{Corresponding author:}

Dr. Benksim Abdelhafid. Higher Institute of Nursing Professions and Health Techniques, Health Department of Marrakech-Safi, 40000 Marrakesh, Morocco.

Tel:+212-661197370, E-mail: benksima@gmail.com and benksim2018@outlook.fr

Received: April 26, 2020, Accepted: May 18, 2020, Published: June 2020

iThenticate screening: May 18, 2020, English editing: June 14, 2020, Quality control: June 12, 2020

This article has been reviewed / commented by three experts

(C) 2020 The Authors. This is an open access article under the terms of the Creative Commons Attribution-NonCommercialNoDerivs License, which permits use and distribution in any medium, provided the original work is properly cited, the use is non-commercial and no modifications or adaptations are made. 
major public events; and closed schools, libraries and factories. China stated in March 2020 that the crisis was coming to an end in its territory (5)

In Europe, the containment strategy differs from one country to another from Sweden to Italy via Germany $(3,4)$. In response, many European countries implemented late interventions, including case isolation, school closings and large-scale social distancing, including local and national closings. Though, partial compliance with instructions and the lack of immediate results have sometimes been criticized, particularly in Italy, Spain and France where the epidemic has claimed many victims $(2,3)$. In the United Kingdom and the Netherlands, the approach initially adopted was that of "collective immunity" which inevitably entails societal and personal sacrifice leading to numerous cases of hospitalization and death. This strategy would allow the virus to spread to increase collective immunity, while protecting the vulnerable population (6). Also, the Netherlands has chosen a more flexible package; it was late to close its schools and restaurants and did not order a complete foreclosure (7). In addition, the German authorities have been supported by the multiplication of tests and the quarantine of positive cases, which is not the case in most countries (8). Nevertheless, despite the number of imported cases producing local chains of transmission, Singapore succeeded in controlling the COVID-19 epidemic without seriously disrupting daily life. In addition, Singapore and South Korea have implemented massive filtering campaigns and technological monitoring of citizens via smartphones, credit cards, or video surveillance in order to stop discrete epidemics and carry out the rigorous follow-up of contacts. This inevitable long-term geolocation has given rise to numerous criticisms of respect for individual rights (9). Currently, it is imperative that current interventions remain in place and those trends in cases and deaths are closely monitored in the coming weeks to reassure that transmission of COVID-19 is slowing.

\section{End of COVID-19 Containment in Morocco: Success, Risks, and Prospects}

Recently, specialists have indicated that having a high rate of infected people was necessary to see the epidemic recede definitively (6). Besides, if containment was a mandatory decision to limit the health crisis, the end of containment seems much more problematic and would provokes heated debates around the world. This process would not mean the end of the health crisis; therefore, it is prospective that this event would not be at the same time for everyone. All countries will have to learn to live with the virus while waiting for the discovery of a new ideal vaccine to restore our normal life (10). However, faced with the risk of a second wave, the operation could prove catastrophic if a strict isolation system was not put in place.

A neighboring country of Europe, Morocco has implemented rigorous health, social and economic measures since the detection of a first imported case of COVID-19 on March 2, 2020. Then, on March 13, 2020, the country implemented social separation which included on March 15, the closing of its borders, on March 16, the suspension of studies, on March 20 complete containment, and the obligation to wear masks on authorized trips on April 06 (11). Knowing that there were not yet specific treatments or vaccines, it seems that the situation is relatively under control and the country is moving towards controlling the epidemic and must prepare for the new challenge of ending of containment while awaiting the discovery of an adequate vaccine (12). This new step is justified by the positive effects of social isolation which have made it possible to reduce the number of patients in intensive care, the rate of virus reproduction (R0), a slight increase in new cases and a drop in mortality rate. Nevertheless, the lifting of containment must be in a progressive "step by step" manner over a prolonged period. It must be accompanied by the need to reduce new positive cases, to wear mandatory masks, to extend massive screening tests, especially among employees, the elderly, and people with low immunity. Moreover, essential travel would need be authorized, teleworking to be continued and many companies allowed to reopen while respecting hygiene measures and physical distancing. For at least a month, it would be necessary to continue testing citizens, treating patients, limiting interregional travel, avoiding large sports gatherings, religious events, concerts, restaurants, cafes, and schooling, except for young persons who are less susceptible to COVID-19 infection. According to earlier study, there were no deaths in children or in adults under the age of 24 years (13). In addition, people who may come into contact with the virus should receive adequate treatment and be quarantined at home or in special facilities where they could be monitored. However, the voluntary search for digital contacts is far from being a reality today in containing the coronavirus in Morocco (9). Furthermore, the containment must be gradually lifted at the local level, and then extended to specific measures with greater geographic coverage by implementing appropriate actions and redeploying rapid measures in the event of new infections. Moroccan regions should envisage a gradual end of containment by limiting unnecessary interregional movements. Regions deemed less affected, such as Beni MellalKhénifra, Dakhla-Oued Ed-Dahab, Guelmim Oued-Noun, Laâyoune-Sakia El-Hamra, and Oriental will be able to adopt a much more flexible containment lifting process by authorizing the reopening of small businesses and even 
gatherings of people depending on the evolution of the epidemic situation. In summary, the gradual end of containment allows health services to recover from the first wave and strengthen their capacities to cope with the second. Consequently, a deadly resurgence of the pandemic would be possible in the event of a hasty end of containment.

\section{Conclusions and recommendations}

According to WHO recommendations, the virus will continue to circulate among us more than ever and the population must continue to confront it. Admittedly, a diversified diet, regular physical activity, adequate sleep and anti-stress sessions play an essential role in the proper functioning of the immune system and are indispensable against a possible new wave of virus infection. Nevertheless, the world must prepare for general containment towards gradual lifting of restrictions, taking into account drastic measures such as a significant reduction in the number of hospitalizations and/or new cases over an extended period, the capacity of systems including the number of beds, quarantine areas, stocks of pharmaceuticals along with a sufficient capacity for large-scale detection of suspected cases.

\section{Acknowledgments:}

Authors want to acknowledge the Editorial office of journal and all the anonymous reviewers.

\section{Conflict of Interest:}

There is no conflict of interest to be declared.

\section{Authors' contributions:}

All authors contributed to this project and article equally. All authors read and approved the final manuscript.

\section{References:}

1) Daoudi S. The war on covid-19: the $9 / 11$ of health security? Policy Center for the New South, Rabat; Maroc. Available from: https:/www.policycenter.ma/sites/default/files/PP\%20-\%202006\%20\%28\%20Salma\%20Daoudi\%20\%29\%20COVID-19.pdf

2) COVID-19 Worldwide Dashboard - WHO Live World Statistics. Available from: https://www.worldometers.info/coronavirus/?utm_campaign=homeAdUOA?Si\#countries

3) Flaxman, S., Mishra, S., Gandy, A. et al. Estimating the effects of non-pharmaceutical interventions on COVID-19 in Europe. Nature, June 2020. doi: 10.1038/s41586-020-2405-7 PMid:32512579

4) Rocklov, J. Covid-19 health care demand and mortality in Sweden in response to non-pharmaceutical (NPIs) mitigation and suppression scenarios. medRxiv. May 2020. doi: 10.1101/2020.03.20.20039594

5) Chen, S., Yang, J., Yang, W., Wang, C., \& Bärnighausen, T. COVID-19 control in China during mass population movements at New Year. Lancet, 2020; 395 (10226), 764-6. doi: 10.1016/S01406736(20)30421-9

6) Kwok, K. O., Lai, F., Wei, W. I., Wong, S. Y. S., \& Tang, J. W. Herd immunity-estimating the level required to halt the COVID-19 epidemics in affected countries. J. Infect. 2020, 80: e32-e33. doi: 10.1016/j.jinf.2020.03.027 PMid: 32209383 PMCid: PMC7151357

7) Enserink, M., \& Kupferschmidt, K. (2020). With COVID-19, modeling takes on life and death importance. Science. Mar 2020. 367; 6485: 1414-5 doi: 10.1126/science.367.6485.1414-b PMid: 32217707

8) Tellis, G. J., Sood, A., \& Sood, N. How Long Should Social Distancing Last? Predicting Time to Moderation, Control, and Containment of COVID-19. Predicting Time to Moderation, Control, and Containment of COVID-19 (March 28, 2020). doi: 10.2139/ssrn.3562996

9) Lee, V. J., Chiew, C. J., \& Khong, W. X. Interrupting transmission of COVID-19: lessons from containment efforts in Singapore. J. Travel Med. doi: 10.1093/jtm/taaa039 PMid: 32167146 PMCid: PMC7107552

10) Lawton G. How do we leave lockdown?, New Scientist. 2020; 246(3277):10-12. doi: 10.1016/S02624079(20)30706-5

11) Pandémie de Covid-19 au Maroc, Wikipédia, L'Encyclopédie Libre (2020) ; Available from: https://fr.wikipedia.org/wiki/Pand\%C3\%A9mie_de_Covid-19_au_Maroc

12) Lee PI, Hu YL, Chen PY, Huang YC, Hsueh PR. (2020). Are children less susceptible to COVID-19?. J Microbiol Immunol Infect. 2020 Feb 25. pii: S1684-1182(20)30039-6. PMID: 32147409, PMCID: PMC7102573, doi: 10.1016/j.jmii.2020.02.011 